\title{
Repeated Exposure to 4-Methyl-2,4-bis(4-hydroxyphenyl)pent- 1-ene (MBP), an Active Metabolite of Bisphenol A, Aggressively Stimulates Breast Cancer Cell Growth in an Estrogen Receptor $\beta(\mathrm{ER} \beta)$-Dependent Manner
}

\author{
Masayo Hirao-Suzuki, Shuso Takeda, Katsuhiro Okuda, Masufumi Takiguchi, \\ and Shin'ichi Yoshihara
}

\begin{abstract}
Laboratory of Xenobiotic Metabolism and Environmental Toxicology, Faculty of Pharmaceutical Sciences, Hiroshima International University (HIU), Kure, Hiroshima, Japan (M.H.-S., S.T., M.T., S.Y.); and Department of Legal Medicine, Asahikawa Medical University, Asahikawa, Hokkaido, Japan (K.O.)
\end{abstract}

Received August 28, 2018; accepted December 10, 2018

\begin{abstract}
Bisphenol A (BPA), recognized as an endocrine disruptor, is thought to exert its activity through a mechanism involving the activation of estrogen receptors (ERs) $\alpha / \beta$. However, a major problem is that very high concentrations of BPA are required (i.e., those in excess of environmental levels) for effective activation of $\mathrm{ER} \alpha / \beta$-mediated transcriptional activities in vitro, despite the BPA-induced estrogenic effects observed in vivo. To elucidate the causal reasons, we successfully identified a BPA metabolite, 4-methyl-2,4-bis(4-hydroxyphenyl)pent-1-ene (MBP), which exhibits highly potent estrogenic activity both in vivo and in vitro. We have focused on the biologic relationship between breast tumor promotion and MBP/BPA, because BPA is considered to
\end{abstract}

\section{Introduction}

Ordinarily, humans are exposed to many chemicals present in the environment. Many of them, such as bisphenol A (BPA), can be used to produce polycarbonate and epoxy resins; these are used in a variety of consumer products, including baby bottles, food can lining, and dental sealant (Brotons et al., 1995; Olea et al., 1996; Yamamoto and Yasuhara, 1999). Thus, we may be exposed to BPA monomers that leach out from those materials. According to one study (Calafat et al., 2008), BPA has been detected in $>90 \%$ of the human urine samples tested in the United States, which suggests the widespread nature of exposure to BPA. An accumulation of experimental evidence suggests the adverse health effects considered to be attributable to BPA include disorders of reproductive function, obesity, and cancer. In addition, there is reasonable evidence, such as breast/prostate tumor-promoting

This study was supported in part by a Grant-in-Aid for Scientific Research (C) $[17 \mathrm{~K} 08402$, (to S.T.)] from the Japan Society for the Promotion of Science (JSPS) KAKENHI.

https://doi.org/10.1124/mol.118.114124. be a human carcinogen owing to its breast tumor-promoting properties. In general, humans are exposed to many endocrine disruptors, including BPA. In the present study, we used the ER $\alpha / \beta$-positive human breast cancer cell line MCF-7 as an experimental model to investigate the effects of repeated exposure to BPA/MBP at concentrations found in the environment on the expression of $\mathrm{ER} \alpha / \beta$ and to determine the particular ER subtype involved. We demonstrated that repeated exposure to MBP, but not to BPA, significantly downregulated $\mathrm{ER} \alpha$ protein expression and stimulated the proliferation of MCF-7 cells through the activation of ER $\beta$ mediated signaling.

ABBREVIATIONS: ANOVA, analysis of variance; BPA, bisphenol A; CAS, Chemical Abstracts Service; E2, 17 $\beta$-estradiol; ER, estrogen receptor; ERE, estrogen-responsive element; FBS, fetal bovine serum; MBP, 4-methyl-2,4-bis(4-hydroxyphenyl)pent-1-ene; MEM $\alpha$, minimum essential medium $\alpha ; \mathrm{PC}_{10}$, transcriptional activities equivalent to $10 \%$ of the value of the positive control; PHTPP, 4-[2-phenyl-5,7-bis(trifluoromethyl)pyrazolo[1,5-a]-pyrimidin-3-yl]phenol; PI, propidium iodide; RT-PCR, reverse transcription-polymerase chain reaction. 
that the estrogenic activity of MBP was approximately 500fold more potent than that of BPA in in vivo experiments performed in ovariectomized Wistar rats (Okuda et al., 2010). In addition, potent estrogenic effects were observed in experiments on medaka (Oryzias latipes) and zebrafish, in which MBP exhibited approximately 250-fold and 1000-fold stronger estrogenic activity than did BPA (Ishibashi et al., 2005; Moreman et al., 2018). As mentioned above, MBP is thought to be a key candidate for resolving the difference of in vitro and in vivo effects of BPA. We reported that MBP exhibited comparable $\mathrm{EC}_{50}$ values for the activation of human $\mathrm{ER} \alpha$ and $\mathrm{ER} \beta$ transiently expressed in NIH/3T3 cells (Yoshihara et al., 2004). Under physiologic conditions, the expression of ERs is regulated by their ligand, E2 (Nirmala and Thampan, 1995; Nawaz et al., 1999; Duong et al., 2006); this phenomenon suggested that prolonged, but not transient, exposure to MBP may lead to a change in the expression of $\mathrm{ER} \alpha / \beta$, which may enhance the malignancy of cancer cells.

Ligand-mediated ER degradation has been demonstrated in different cell types, including human breast cancer MCF-7 cells, which are known to be $\mathrm{ER} \alpha / \beta$ positive (Nirmala and Thampan, 1995; Nawaz et al., 1999; Speirs et al., 1999a; Duong et al., 2006). The proliferation of MCF-7 cells is stimulated by E2, which results from the activation of the E2/ER $\alpha$ signal transduction pathways (Foster et al., 2001). Unlike $\operatorname{ER} \alpha$, the physiologic role of $\operatorname{ER} \beta$ is not fully understood; however, the $\beta$-type ER is recognized as a functional repressor of $\mathrm{ER} \alpha$ owing to its ability to heterodimerize with $\mathrm{ER} \alpha$ when they are coexpressed (Cowley et al., 1997; Ogawa et al., 1998; Pettersson et al., 2000; Powell and Xu, 2008). Furthermore, it has been suggested that ER $\beta$ may be a tumor suppressor owing to its reduced expression during cancer development (Iwao et al., 2000). However, the accumulated evidence suggests that $\operatorname{ER} \beta$ also acts as a mediator of estrogen action in breast cancer cells (Speirs et al., 1999a; Hamilton et al., 2015; Ma et al., 2017). Thus, in the present study, we investigated the effects of repeated exposure to BPA, together with MBP, at concentrations similar to environmental levels on the expression of $\mathrm{ER} \alpha / \beta$, and investigated the ER subtype that was involved in these effects. Our results indicated that repeated exposure to $\mathrm{MBP}$, but not $\mathrm{BPA}$, downregulated $\mathrm{ER} \alpha$ protein expression and stimulated the proliferation of MCF-7 cells through the activation of $\operatorname{ER} \beta$.

\section{Materials and Methods}

Reagents. ICI 182,780 (fulvestrant) (purity, $\geq 98 \%$ ) [Chemical Abstracts Service (CAS) number 129453-61-8] and 4-[2-phenyl-5,7bis(trifluoromethyl)pyrazolo[1,5- $a$ ]-pyrimidin-3-yl]phenol (PHTPP) (purity, $\geq 98 \%$ ) (CAS number 805239-56-9) were purchased from Santa Cruz Biotechnology (Dallas, TX) and Sigma-Aldrich (St. Louis, MO), respectively. BPA [4,4'-(propane-2,2-diyl)diphenol] (purity, $\geq 99 \%$ ) (CAS number 80-05-7) was purchased from Nacalai Tesque (Kyoto, Japan). The chemical synthesis of MBP (purity, $\geq 98 \%$ ) (CAS number 13464-24-9) was performed in accordance with previously reported methods (Yoshihara et al., 2004; Okuda et al., 2010). E2 (purity, $\geq 98 \%$ ) was purchased from FUJIFILM Wako Pure Chemical Corporation (Osaka, Japan).

Cell Cultures and Chemical Treatments. The cell culture conditions and methods used were based on previously described procedures (Takeda et al., 2013, 2016; Suzuki et al., 2017a). Briefly, the human breast cancer cell lines MCF-7 and MDA-MB-231 were routinely grown in phenol red-containing minimum essential medium
$\alpha(\operatorname{MEM} \alpha)$ (FUJIFILM Wako Pure Chemical Corporation), supplemented with $10 \mathrm{mM}$ HEPES, 5\% fetal bovine serum (FBS), penicillin $(100 \mathrm{U} / \mathrm{ml})$, and streptomycin $(100 \mu \mathrm{g} / \mathrm{ml})$, in a humidified incubator in an atmosphere of $5 \% \mathrm{CO}_{2}$ at $37^{\circ} \mathrm{C}$. Twenty-four hours prior to the treatment of cells with chemicals, the culture medium was changed to phenol red-free MEM $\alpha$ (FUJIFILM Wako Pure Chemical Corporation), supplemented with $10 \mathrm{mM}$ HEPES, 5\% dextran-coated charcoal-treated FBS, penicillin (100 U/ml), and streptomycin $(100 \mu \mathrm{g} / \mathrm{ml})$. ICI 182,780 , PHTPP, BPA, and MBP were prepared in cell culture-grade dimethylsulfoxide. In the experiments in Fig. 1, B and C, the cells were treated with ICI 182,780 and PHTPP for 24 hours after cDNA transfection [see Transfection and Luciferase Analysis (Dual-Luciferase Assay)] and then collected for the dualluciferase\& assay. The details of the chemical treatment method, except for the experiment of Fig. 1, are shown in Fig. 2B. The first treatment (treatment 1 ) comprised vehicle (for the control) or ligands [BPA or MBP, for the booster (-/+)]. After 24 hours of the first treatment, the culture medium was changed to fresh phenol red-free $\operatorname{MEM} \alpha$, and the cells were further treated with the vehicle [for control or booster (-)] or with ligands [for booster (+); treatment 2]. The results shown in Fig. 8 are from experiments performed after MBP treatment in the presence or absence of PHTPP. The results shown in Fig. 9 are from experiments in which the cells were treated with $2 \mathrm{nM} \mathrm{MBP}$ for 48 hours without alteration of the culture medium (indicated as $2 \mathrm{nM} \mathrm{MBP}$ ), to compare the conditions between $2 \mathrm{nM}$ MBP and booster (+) (see Fig. 9A). After a total treatment time of 48 hours, the cell samples were collected for the dual-luciferase assay, cell proliferation analysis, cell cycle analysis, Western blotting, and real-time reverse-transcription polymerase chain reaction (RT-PCR).

Transfection and Luciferase Analysis (Dual-Luciferase Assay). The experiments were performed as described previously, with minor modifications (Takeda et al., 2013; Okazaki et al., 2018). In brief, 24 hours prior to transfection, MCF-7 and MDA-MB-231 cells $\left(5 \times 10^{4}\right.$ cells/well) were seeded in 24 -well plates containing $\operatorname{MEM} \alpha$. Each expression plasmid was transfected by using Lipofectamine LTX with PLUS reagent (Thermo Fisher Scientific, Waltham, MA). DNA mixtures containing $300 \mathrm{ng}$ of estrogen-responsive element (ERE) ${ }_{3}$ luciferase plasmid were cotransfected with $2 \mathrm{ng}$ of Renilla luciferase reporter plasmid in 24 -well plates. At 24 hours after transfection, the cells were washed with phosphate-buffered saline, the culture medium was exchanged for phenol red-free MEM $\alpha$-supplemented with 5\% dextran-coated charcoal-treated FBS, and chemical treatments were applied in accordance with the methods described in Cell Cultures and Chemical Treatments. After 24 or 48 hours of treatment, cell extracts were prepared in $100 \mu \mathrm{l}$ of passive lysis buffer (Promega, Madison, WI), from which $20 \mu \mathrm{l}$ was extracted to perform the firefly luciferase and Renilla luciferase assays (Dual-Luciferase Reporter Assay System; Promega). The ratio of firefly luciferase activity to Renilla luciferase activity was presented as the relative luciferase activity.

Cell Proliferation Analysis (MTS Assay). The MTS assay was performed as described previously (Takeda et al., 2016; Suzuki et al., $2017 \mathrm{~b}$ ). Briefly, the cells were seeded into 96 -well plates at a density of $\sim 5 \times 10^{3}$ cells/well in the cell proliferation study. After chemical treatments or incubation, the degree of cell proliferation was analyzed by using the CellTiter 96 AQueous One Solution Cell Proliferation Assay (MTS reagent; Promega).

Cell Cycle Analysis. The chemically treated cells were harvested $\left(2 \times 10^{5}\right.$ cells $/$ sample $)$ and fixed in $70 \%$ ethanol at $4^{\circ} \mathrm{C}$ overnight. The fixed cells were harvested and resuspended in $450 \mu \mathrm{l}$ of PBS containing $50 \mu \mathrm{g} / \mathrm{ml}$ propidium iodide (PI) (Nacalai Tesque) and $100 \mu \mathrm{g} / \mathrm{ml}$ RNaseA (Qiagen, Inc., Hilden, Germany) and incubated at $26^{\circ} \mathrm{C}$ for 30 minutes in the dark. Finally, the stained cells were analyzed by using a FACSCalibur Flow Cytometer (BD Biosciences, Franklin Lakes, NJ). A minimum of $1 \times 10^{4}$ cells was counted per sample. The obtained results were analyzed by using ModFit LT version 3.0 (Verity Software House, Topsham, ME). 




B



ICI 182,780:

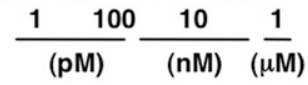

C

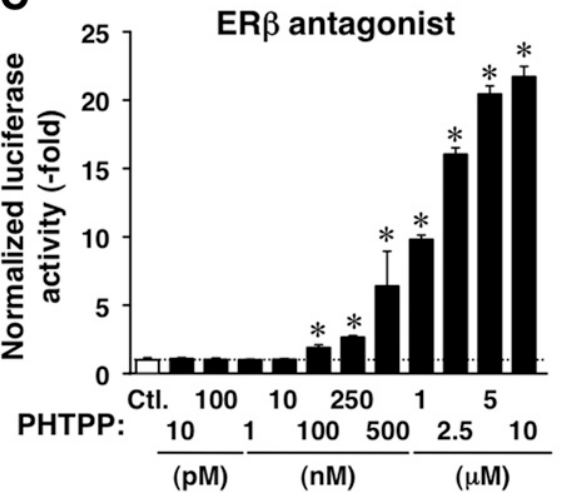

Fig. 1. ER $\beta$ inhibition of transcriptional activity mediated by ERs in MCF-7 cells. (A) A model of $\mathrm{ER} \alpha$ signaling abrogation by ER $\beta$. (B and C) MCF-7 cells were transiently transfected with an ERE-luciferase reporter plasmid. After transfection, the cells were treated with ICI 182,780 (1 pM to $1 \mu \mathrm{M})(\mathrm{B})$ or PHTPP $(10 \mathrm{pM}$ to $10 \mu \mathrm{M})(\mathrm{C})$. The control sample was incubated with vehicle (indicated as Ctl.). After 24 hours, the cells were harvested and assayed for luciferase activity, with all transfection efficiencies normalized by using the internal Renilla control plasmid. The data are presented as the mean \pm S.D. $(n=3)$ fold induction from the vehicle-treated control (indicated as 1). Significant differences [for (B and C) one-way ANOVA, followed by Dunnett's post hoc test] compared with control are marked with asterisks $(* P<0.05)$.

Antibodies and Western Blotting. Antibodies specific for ER $\alpha$ (ab79413; Abcam, Cambridge, MA), ER $\beta$ (ab3576; Abcam), and $\beta$-actin (sc-47778; Santa Cruz Biotechnology) were used. Whole-cell extracts were prepared by using lysis buffer (50 mM HEPES-NaOH at $\mathrm{pH} 7.5$, $25 \mathrm{mM} \mathrm{NaCl}, 1 \% \mathrm{NP} 40$, and $1 \mathrm{mM}$ phenylmethylsulfonyl fluoride) supplemented with cOmplete Mini Protease Inhibitor Cocktail (Sigma-Aldrich). The cell extracts that were transfected with human $\mathrm{ER} \alpha$ or ER $\beta$ cDNA were used as the positive control (indicated as Std.; Figs. 6 and 9B). SDS-PAGE/Western immunoblotting was performed based on previously described procedures (Suzuki et al., 2017b). The antibodies for $\operatorname{ER} \alpha$ (1:2000 dilution), $\operatorname{ER} \beta$ (1:2000 dilution), and $\beta$-actin (1:4000 dilution) were used as the primary antibodies for the detection of $\mathrm{ER} \alpha, \mathrm{ER} \beta$, and $\beta$-actin, respectively. Anti-rabbit IgG (1:10,000 dilution) and anti-mouse IgG (1:10,000 dilution) antibodies conjugated with peroxidase were used as the secondary antibodies. Luminata Forte Western HRP Substrate (Millipore, Billerica, MA) was used for the detection of blotted bands. The quantification of band intensities was performed by using ImageJ 1.46r software (http://imagej.nih.gov/ij/), and the obtained values were normalized to $\beta$-actin, an endogenous control.

Preparation of Total RNA and Real-Time RT-PCR. Real-time RT-PCR was performed as described previously (Okazaki et al., 2018). Briefly, total RNA was prepared from MCF-7 cells by using TRIzol RNA Isolation Reagent (Thermo Fisher Scientific). cDNA was synthesized from $600 \mathrm{ng}$ of total RNA using the High-Capacity cDNA Reverse Transcription Kit (Thermo Fisher Scientific). Real-time RT-PCR was



Fig. 2. Structures and experimental scheme for the treatment with BPA or MBP. (A) The structures of BPA and MBP. (B) The experimental scheme for treatment with BPA or MBP. In treatment (1), the cells were treated with vehicle for control or ligands (BPA or MBP) for booster (-) and booster (+). In treatment (2), the culture medium was changed after 24 hours of treatment (1), and the cells were then treated with vehicle for control/booster $(-)$, or ligands for booster $(+)$. The details of the experimental scheme for the treatments are described in the Materials and Methods. After chemical treatment for a total of 48 hours, samples of the treated cells were collected for the analysis of gene expression, luciferase activity, cell proliferation, and cell cycle.

performed using an Applied Biosystems StepOne Real-Time PCR System (Thermo Fisher Scientific) with Fast SYBR Green Master Mix (Thermo Fisher Scientific). The following primers used: ER $\alpha$ (sense), 3'-GAA AGG TGG GAT ACG AAA AGA CC-5'; ER $\alpha$ (antisense), 3 'GCT GTT CTT CTT AGA GCG TTT GA-5'; 18S-ribosomal RNA (sense), 3'-CGG CTA CCA CAT CCA AGG A-5'; and 18S-ribosomal RNA (antisense), 3'-GCT GGA ATT ACC GCG GCT-5'. The mRNA expression of $E R \alpha$ in each sample was normalized to the corresponding mRNA expression of $18 S$-ribosomal RNA.

Data Analysis. The $\mathrm{EC}_{50}$ values of $\mathrm{BPA}$ and $\mathrm{MBP}$ were determined, and the concentrations of the compounds that elicited ERE-mediated transcriptional activities equivalent to $10 \%$ of the value of the positive control (1 nM E2) were defined as $\mathrm{PC}_{10}$ (EPA, 2011). Dose-response curves were fitted by using SigmaPlot 11 software (Systat Software, Inc., San Jose, CA). Differences were considered significant for $P$ values less than 0.05 . The statistical significance of differences between the two groups was calculated by using the Student's $t$ test. Other statistical analyses, such as Dunnett's or Tukey-Kramer tests, were performed as post hoc tests after the analysis of variance (ANOVA) (details are indicated in figure legends). These calculations were performed by using StatView 5.0 J software (SAS Institute Inc., Cary, NC).

\section{Results}

ER $\beta$ as a Negative Regulator of ER $\alpha$-Mediated Transcriptional Activity. It has been reported that estrogen signaling can be modulated by several methods; for 

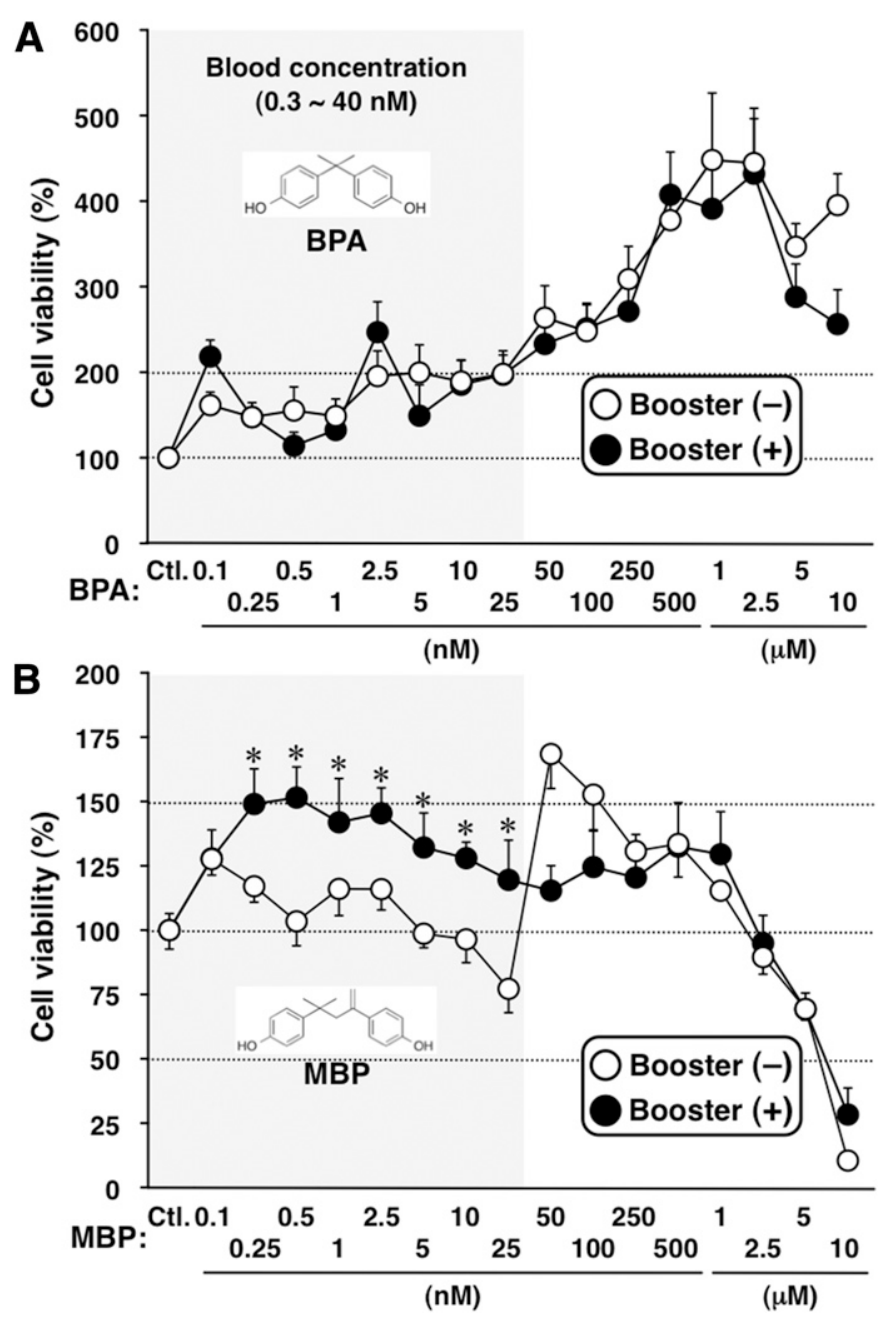

Fig. 3. Effects of repeated exposure of BPA and MBP on the proliferation of MCF-7 cells. MCF-7 cells were exposed to BPA $(0.1 \mathrm{nM}$ to $10 \mu \mathrm{M})(\mathrm{A})$ or $\mathrm{MBP}(0.1 \mathrm{nM}$ to $10 \mu \mathrm{M})(\mathrm{B})$, and then cell proliferation was measured. The chemical treatments and cell proliferation analysis were performed in accordance with the methods described in Materials and Methods. The control sample (indicated as Ctl.) comprised incubation with vehicle alone. The open and closed circles represent booster $(-)$ and booster (+), respectively. The data are presented as the mean \pm S.D. $(n=6)$ of percentage relative to the control. Significant differences [for (B) two-way ANOVA, repeated (related) measures with Tukey-Kramer's post hoc test] are marked with asterisks $(* P<0.05) . P$ values were for the line graph obtained when MBP was treated at concentrations up to $25 \mathrm{nM}$, compared with the booster (-) line graph.

example, when $\mathrm{ER} \alpha$ and $\mathrm{ER} \beta$ are simultaneously expressed in cells, E2/ER $\alpha$-mediated transcriptional activity can be suppressed by the $\beta$-type ER in MCF-7 and other cell lines, including in human embryonic kidney 293 cells cotransfected with $\mathrm{ER} \alpha / \mathrm{ER} \beta$ expression plasmids (see the model described in Fig. 1A) (Pettersson et al., 2000; Takeda et al., 2013; Takeda, 2014). It is generally considered, especially in in vitro conditions, that the expression of the individual ERs is one of the key determinants for the output of E2 signaling. ER $\alpha$-positive MCF-7 cells produce endogenous E2, but at very low levels, to stimulate their own growth via $\mathrm{E} 2 / \mathrm{ER} \alpha$ and express the $\mathrm{ER} \beta$ subtype (Miki et al., 2007). Therefore, in this study, we selected the MCF-7 cell line as a model and investigated the effects of two established antagonists, ICI 182,780 and PHTPP, which are specific for ER $\alpha$ and $\mathrm{ER} \beta$, respectively, in the absence of exogenous E2. As shown in
A
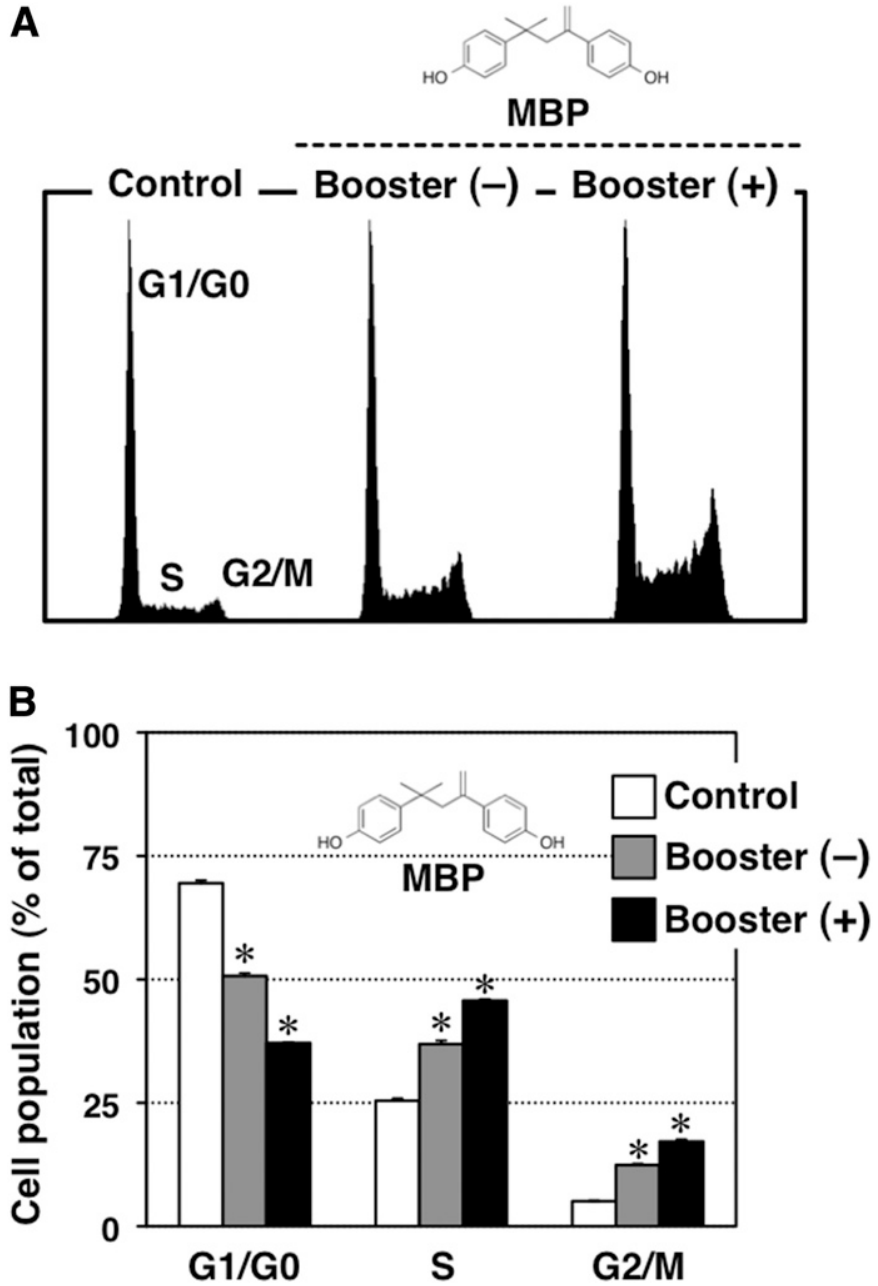

Fig. 4. Repeated exposure of MBP stimulated cell cycle progression in MCF-7 cells. The MCF-7 cells were treated with $1 \mathrm{nM}$ MBP for booster (-) and booster $(+)$ and then stained with PI. The distribution of cells in each phase of the cell cycle was determined by flow cytometric analysis of PI staining of the DNA. (A) Representative histograms are shown. (B) The expected phase of the cell cycle and the percentage of cells in each phase are indicated. The data are presented as the mean \pm S.D. $(n=3)$. Significant differences [for (B) two-way ANOVA, followed by Dunnett's post hoc test] compared with control are marked with asterisks $(* P<0.05)]$.

Fig. 1, B and C, ER/ERE-mediated transcriptional activity in MCF-7 cells was inhibited by ICI 182,780 in a concentrationdependent manner up to $1 \mu \mathrm{M}$, whereas PHTPP stimulated the transcriptional activity in a concentration-dependent manner up to $10 \mu \mathrm{M}$. These data strongly suggested that E2/ER-mediated estrogen signaling was triggered mainly by the $\mathrm{ER} \alpha$ subtype and that $\mathrm{ER} \beta$ exerted a negative impact on $\mathrm{ER} \alpha$ in the conditions in which cells coexpressed both subtypes (Fig. 1A).

MBP as a Positive Stimulator of ER-Positive Breast Cancer Cell Proliferation in a Repeated ExposureDependent Manner. Humans are routinely exposed to a variety of environmental chemicals, including BPA, which can act as ligands and stimulate ERs. It is important to investigate whether repeated exposure of BPA to cells that express both ER subtypes may result in the perturbation of $\mathrm{ER} \alpha / \mathrm{ER} \beta$ expression, which may be coupled with the dysregulation of estrogen receptor signaling. Therefore, we first investigated 

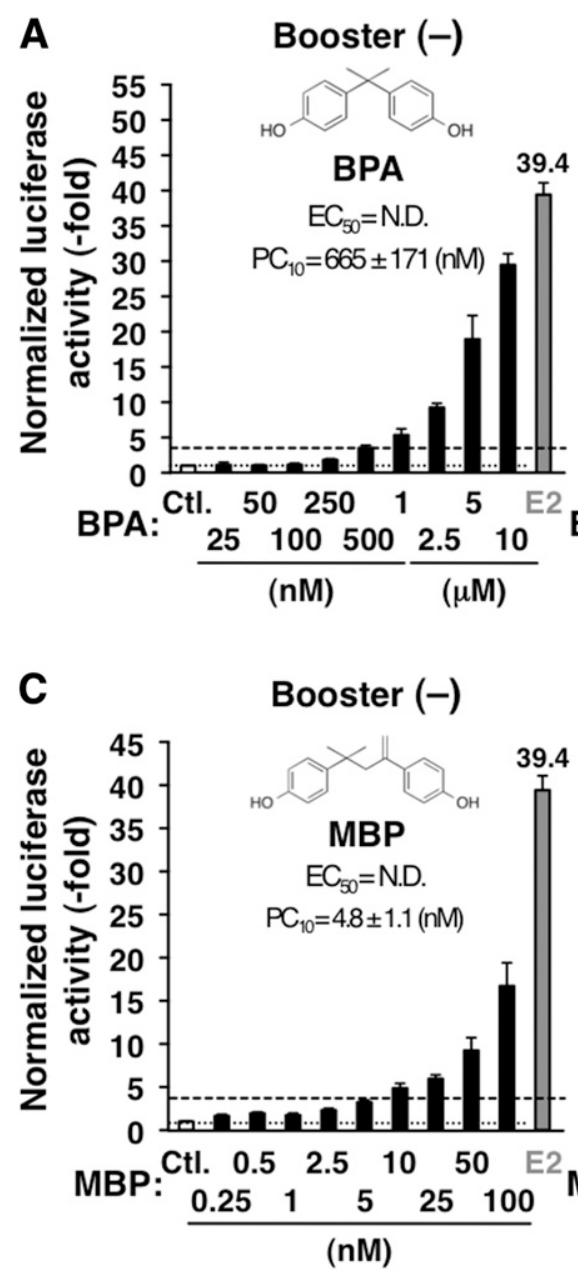

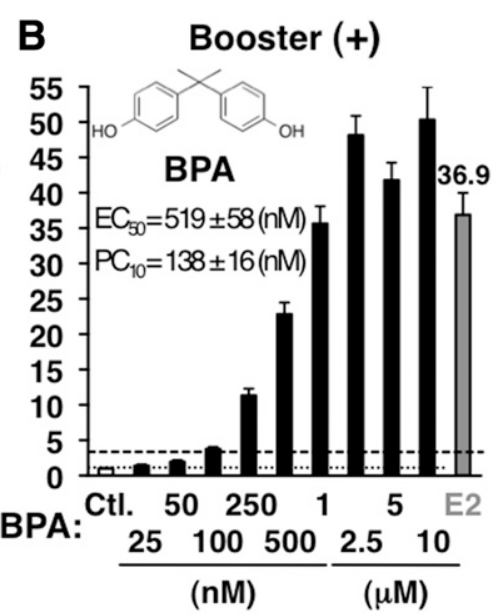

D Booster (+)

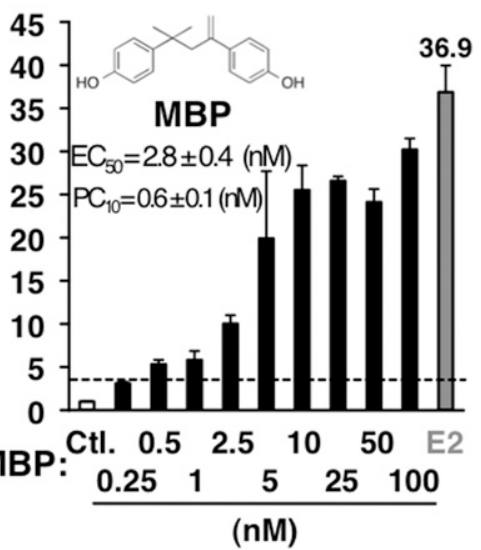

Fig. 5. Effects of repeated exposure of BPA and MBP on transcriptional activity mediated by ERs in ER $\alpha / \beta$-positive MCF-7 cells. MCF-7 cells were transiently transfected with an ERE-luciferase reporter plasmid. After transfection, the cells were treated with BPA ( $25 \mathrm{nM}$ to $10 \mu \mathrm{M})(\mathrm{A}$ and B) or MBP $(0.25$ to $100 \mathrm{nM})(\mathrm{C}$ and D) for booster (-) (left panel) and booster (+) (right panel). The control sample (indicated as Ctl.) was treated with vehicle. After chemical treatment for a total of 48 hours, the cells were harvested and assayed for luciferase activity; all transfection efficiencies were normalized by using the internal Renilla control plasmid. (A-D) $\mathrm{EC}_{50}$ and $\mathrm{PC}_{10}$ values were determined. Details are described in Materials and Methods. The data are presented as the mean \pm S.D. $(n=3)$ of the fold induction from the vehicle-treated control (indicated as 1). N.D., not determined (because of low estrogenic activities not displaying a saturation curve profile). the effects of BPA and its metabolite MBP (structures described in Fig. 2A) on the proliferation of MCF-7 cells. MCF-7 cells were treated with individual bisphenols in accordance with the experimental scheme described in Fig. 2B [i.e., booster (-) vs. booster (+)]. As shown in Fig. 3A, there were no observable effects of repeated exposure of BPA on the proliferation of MCF-7 cells, although BPA stimulated cell proliferation in a concentration-dependent manner up to $10 \mu \mathrm{M}$. In contrast, when the effect of MBP was examined, cell proliferation was positively stimulated by the molecule in a repeated exposure-dependent manner up to $25 \mathrm{nM}$ [i.e., booster (+)]; conversely, MCF-7 cell growth was suppressed by MBP concentrations above $2.5 \mu \mathrm{M}$ (Fig. 3B). To conduct further study of whether the MBP-mediated "booster effects" were dependent on the expression status of ERs in cells, we used the human breast cancer cell line MDA-MB-231, which is ER negative (Weigel and deConinck, 1993; Takeda et al., 2013). MBP did not exert a stimulatory effect on the proliferation of MDA-MB-231 cells (data not shown). To confirm the phenomenon observed in Fig. 3B, cell cycle analysis was performed by using flow cytometry. In support of the MBPmediated upregulation of MCF-7 cell growth, the percentage of cells in the $\mathrm{S}$ phase (i.e., DNA replication), which is a preliminary step in cell division, was clearly increased in an MBP treatment-dependent manner [i.e., 25.4\% for control, $36.9 \%$ for booster (-), and $45.7 \%$ for booster (+)] (Fig. 4, A and B). These results indicated that MBP may positively modulate the proliferation of ER-positive MCF-7 cells through the mitogenic activity of cell cycle acceleration. Thus, questions arose on the nature of the driving force for the MBP-mediated stimulation of MCF-7 cell proliferation associated with the stimulation of cell cycle progression. To address this issue, we studied the effects of BPA and MBP on ER/ERE-mediated transcriptional activity in the presence or absence of repeated exposure (see Fig. 2B). The panels in Fig. 5 show the line graphs representing dose-response profiles for the estrogenic activities of BPA and MBP, together with the data of $1 \mathrm{nM} \mathrm{E2}$, which was used as the positive control. As BPA and MBP displayed lower estrogenic potency in booster ( - ) than in booster $(+)$ conditions, accurate $\mathrm{EC}_{50}$ values were not obtained (indicated as N.D.); thus, we also determined the value of $\mathrm{PC}_{10}$. The comparison of the $\mathrm{EC}_{50}$ values for the activation of ERs by BPA and MBP revealed that remarkable boosting effects were observed after the treatment of both $\mathrm{BPA}$ and $\mathrm{MBP}\left(\mathrm{BPA}: \mathrm{PC}_{10}\right.$ values of $665 \mathrm{nM}$ [booster (-)] vs. $138 \mathrm{nM}$ [booster (+)]; $\mathrm{MBP}: \mathrm{PC}_{10}$ values of $4.8 \mathrm{nM}$ [booster (-)] vs. $0.6 \mathrm{nM}$ [booster (+)] (Fig. 5, A-D). In addition, when focusing on the $\mathrm{EC}_{50}$ values between $\mathrm{BPA}$ and MBP in booster $(+)$ conditions, much lower $\mathrm{EC}_{50}$ values were found for MBP exposure (519 vs. $2.8 \mathrm{nM}$ ) (Fig. 5, B and D).

MBP Induced Downregulation of ER $\alpha$ mRNA/ Protein in a Repeated Exposure-Dependent Manner. It has been reported that the $\operatorname{ER} \alpha$ protein may be subject to ligand-mediated degradation, preferentially in the presence of E2 (i.e., $>1$ nM) (Nirmala and Thampan, 1995; Nawaz et al., 

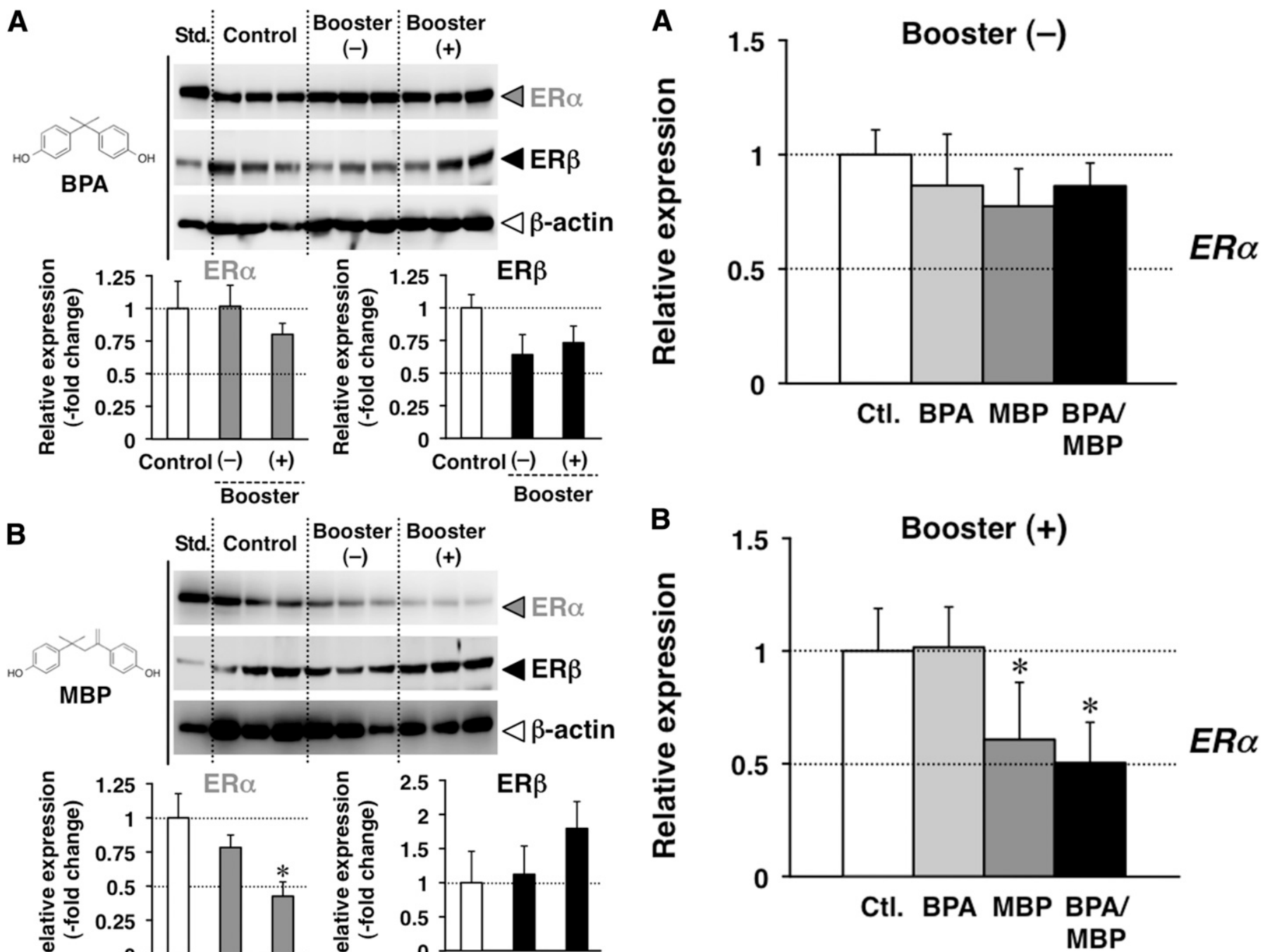

Fig. 7. Effects of repeated exposure of BPA, MBP, and BPA/MBP on the mRNA expression of $E R \alpha$ in MCF-7 cells. Real-time RT-PCR analysis of $E R \alpha$. Booster (-) (A), booster (+) (B) MCF-7 cells were treated with $1 \mathrm{nM}$ BPA, $1 \mathrm{nM}$ MBP, or a combination (BPA/MBP) for booster (-) and booster (+) or vehicle (indicated as Ctl.) for 48 hours. The data are presented as the mean \pm S.D. $(n=6)$ of the fold induction from the vehicle-treated control. Significant differences (two-way ANOVA, followed by Dunnett's post hoc test) compared with control are marked with asterisks $(* P<0.05)$. treatment for a total of 48 hours, total cell lysates were prepared, and Western blotting was performed by using antibodies specific for $\operatorname{ER} \alpha, \operatorname{ER} \beta$, and $\beta$-actin, respectively; $\beta$-actin was used as an internal loading control. The cell lysates prepared with human ER $\alpha$ or ER $\beta$ cDNA-transfected cells were used as the positive control (indicated as Std.) (A and B, bottom panel). The band intensity of ER $\alpha$ (left panel) and ER $\beta$ (right panel) was quantified by using Image J $1.46 \mathrm{r}$ software, and the values were normalized to those of $\beta$-actin. The data are presented as the mean \pm S.D. $(n=3)$ of the fold change from the vehicle-treated control (indicated as 1). Significant differences (two-way ANOVA, followed by Dunnett's post hoc test) compared with control are marked with asterisks $(* P<0.05)$.

1999). Given that MBP behaves as an ER $\alpha$ ligand to induce similar biologic effects in E2, the protein expression of ER $\alpha$ may be downregulated after repeated exposure to MBP. Thus, we analyzed the protein expression of $\mathrm{ER} \alpha$, together with $\mathrm{ER} \beta$, in MCF-7 cells. To use BPA concentrations that reflected those found in biologic samples (Schönfelder et al., 2002; Welshon et al., 2006; Vandenberg et al., 2010), we treated MCF-7 cells with or without repeated exposure of BPA and MBP at $1 \mathrm{nM}$. When the membranes were blotted for BPA, no modulatory effects of $1 \mathrm{nM} \mathrm{BPA}$ on $\mathrm{ER} \alpha / \beta$ expression were

found relative to the control in either condition (booster $+/-$ ); however, the BPA metabolite MBP did reduce the expression of ER $\alpha$ in a treatment-dependent manner without significant alteration of the protein expression of $\mathrm{ER} \beta$, although there was a tendency for $\mathrm{ER} \beta$ to be upregulated (Fig. 6, A and B). To determine whether MBP also affected ER $\alpha$ mRNA expression after repeated exposure, we performed real-time RT-PCR analysis of samples derived from both conditions (booster +/-). Similarly, as shown in Fig. 7, $1 \mathrm{nM} \mathrm{MBP,} \mathrm{but}$ not $1 \mathrm{nM}$ BPA, downregulated the mRNA expression of $E R \alpha$ in a repeated exposure-dependent way. Collectively, these data suggested that the protein expression $\operatorname{ER} \alpha$ can also be downmodulated by MBP via a reduction in $E R \alpha$ mRNA.

Involvement of ER $\beta$ in MBP Estrogenic Action in a Repeated Exposure-Dependent Manner. We further investigated whether the MBP-mediated booster effects were dependent on the basal expression status of ERs (ER $\alpha$ and $\mathrm{ER} \beta$ ); for this, the MDA-MB-231 cell line, which is $\mathrm{ER} \alpha$ 

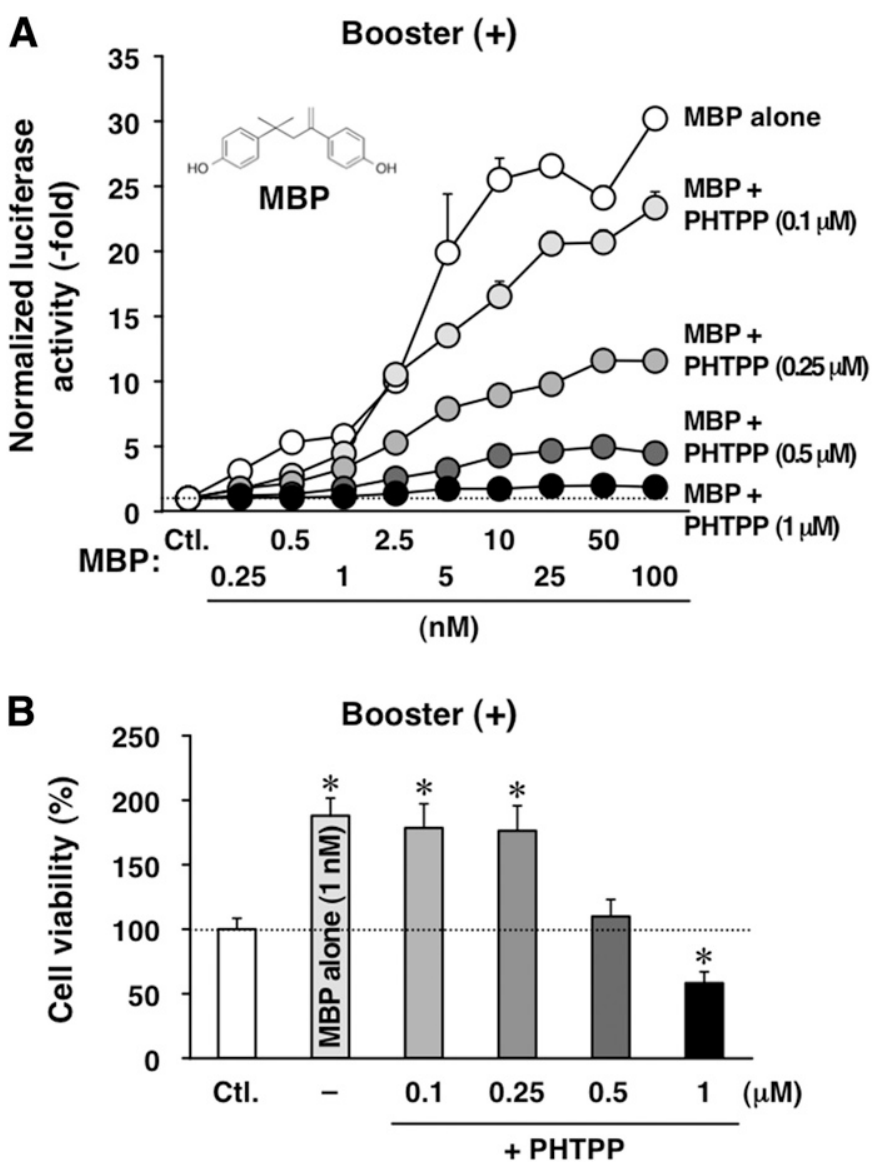

Fig. 8. Effects of the ER $\beta$ antagonist PHTPP on MBP-stimulated transcriptional activity and cell proliferation. (A) MCF-7 cells were transiently transfected with an ERE-luciferase reporter plasmid. After transfection, the cells were treated with $\mathrm{MBP}(0.25-100 \mathrm{nM})$ for booster $(+)$ in the absence (MBP only) or presence of $0.1,0.25,0.5$, or $1 \mu \mathrm{M}$ PHTPP. The control sample was treated with vehicle (indicated as Ctl.). After chemical treatment of a total of 48 hours, the cells were harvested and assayed for luciferase activity; all transfection efficiencies were normalized by using the internal Renilla control plasmid. The data are presented as the mean \pm S.D. $(n=3)$ of the fold induction from the vehicle-treated control (indicated as 1). (B) MCF-7 cells were exposed to $1 \mathrm{nM}$ MBP for booster (+) in the absence or presence of $0.1,0.25,0.5$, or $1 \mu \mathrm{M}$ PHTPP, and then cell proliferation was measured. A control incubation was treated with vehicle alone (indicated as Ctl.). The data are presented as the mean \pm S.D. $(n=6)$ percentage of the control. Significant differences (two-way ANOVA, followed by Dunnett's post hoc test) compared with control are marked with asterisks $(* P<0.05)$.

negative and has a very low expression of ER $\beta$, was used (Weigel and deConinck, 1993; Takeda et al., 2013). As expected, it was clearly shown that neither the MBPmediated stimulation of ER/ERE nor the MBP booster effect were detected in MDA-MB-231 cells (data not shown). To determine whether functional $\mathrm{ER} \beta$ was indeed involved in the MBP-induced transcriptional activation of ER $\beta / E R E$ in MCF7 cells after repeated exposure [i.e., booster $(+)$ conditions], we performed an ERE-luciferase analysis of samples that were treated with MBP in combination with four different concentrations of PHTPP (i.e., 0.1, 0.25, 0.5, and $1 \mu \mathrm{M}$ ), a selective antagonist of the ER $\beta$ subtype. When compared with the MBP-only treatment group at concentrations between 0.25 and $100 \mathrm{nM}$, the MBP-activated transcriptional activities were clearly attenuated by PHTPP in a concentrationdependent manner (Fig. 8A). Furthermore, we analyzed
A
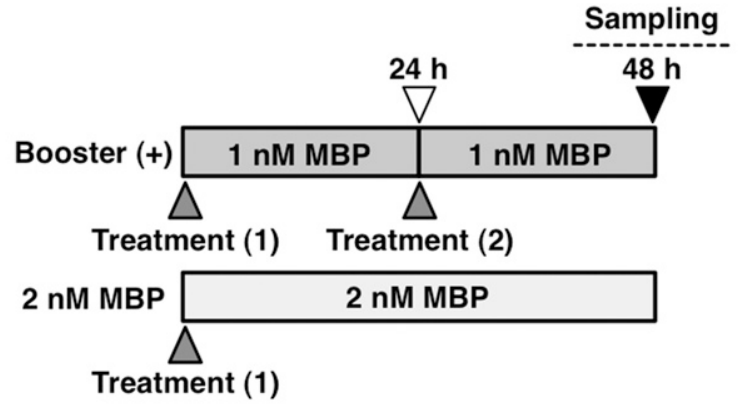

B
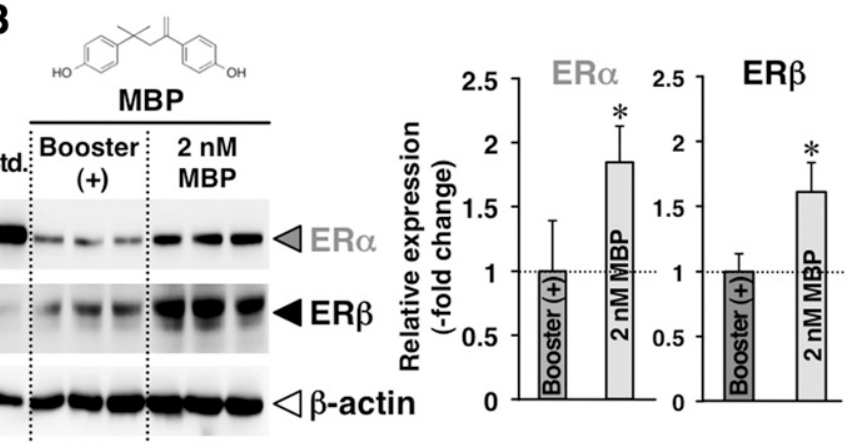

C

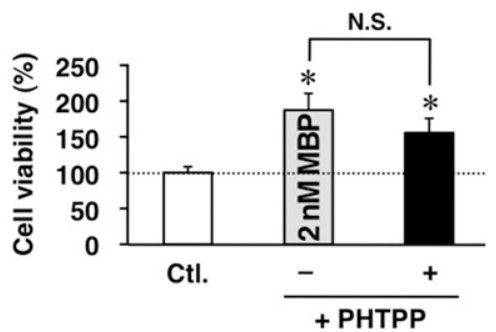

Fig. 9. Comparison of the effects of repeated exposure of $1 \mathrm{nM}$ MBP [booster (+)] and $2 \mathrm{nM}$ MBP exposure on $\mathrm{ER} \alpha / \beta$ protein expression and cell proliferation in MCF-7 cells. (A) The experimental scheme for the treatment with $1 \mathrm{nM}$ MBP for booster (+) or $2 \mathrm{nM} \mathrm{MBP}$ for up to 48 hours. The treatment of $1 \mathrm{nM}$ MBP for booster $(+)$ followed the same method as for booster (+) in Fig. 2B. In contrast, the experimental scheme for $2 \mathrm{nM} \mathrm{MBP}$ treatment involved no culture medium change and additional exposure. (B left panel) Western blotting of $\mathrm{ER} \alpha$ and $\mathrm{ER} \beta$. MCF-7 cells were treated with $1 \mathrm{nM}$ MBP for booster (+) or $2 \mathrm{nM}$ MBP. After chemical treatment for a total of 48 hours, total cell lysates were prepared, and Western blotting of antibodies specific for $\operatorname{ER} \alpha, \operatorname{ER} \beta$, and $\beta$-actin was performed; $\beta$-actin was used as an internal loading control. Cell lysates prepared with human ER $\alpha$ or $\operatorname{ER} \beta$ cDNA-transfected cells were used as the positive control (indicated as Std.). (B, right panel) The band intensity of ER $\alpha$ (left panel) and ER $\beta$ (right panel) was quantified by using ImageJ $1.46 \mathrm{r}$ software, and the values were normalized to $\beta$-actin. The data are expressed as the mean \pm S.D. $(n=3)$ of the fold change from booster (+) cells (indicated as 1$)$. (C) MCF-7 cells were exposed to $2 \mathrm{nM}$ MBP in the presence or absence of $0.5 \mu \mathrm{M}$ PHTPP. After incubation for 48 hours, the cell proliferation was measured. The control sample was treated with vehicle alone (indicated as Ctl.). The data are presented as the mean \pm S.D. $(n=6)$ as a percentage of the control. Significant differences [Student's $t$ test for (B, right panel); oneway ANOVA, repeated (related) measures with Tukey-Kramer's post hoc test for (C)] compared with booster (+) (B) or control (C) are marked with asterisks $(* P<0.05)$. N.S., not significant.

whether the introduction of PHTPP abrogated the MBPenhanced cell proliferation and found that MCF-7 cell proliferation stimulated by MBP was dose-dependently dampened by PHTPP (Fig. 8B). The effects of MCF-7 cells exposed to $1 \mathrm{nM}$ MBP for a total of 48 hours with repeated exposure [i.e., booster (+): $1 \mathrm{nM} \mathrm{MBP} \mathrm{+} 1 \mathrm{nM}$ MBP] or without [i.e., booster $(-): 1 \mathrm{nM} \mathrm{MBP}+$ vehicle instead of MBP] are shown in Figs. 4, $6 \mathrm{~B}, 7$, and $8 \mathrm{~B}$; however, at 24 hours after the first exposure to 




Fig. 10. Summary of the effects of repeated exposure to MBP, an endocrine-disrupting chemical, on human breast cancer cells. ER $\alpha$ signaling tends to be abrogated by coexisting $\operatorname{ER} \beta$ in human breast cancers with no exposure to MBP. In this study, it was revealed that repeated exposure to MBP stimulated ERE-driven transcriptional activity and cell proliferation, even though repeated exposure to MBP induced the downregulation of $\mathrm{ER} \alpha$. Mechanistically, the MBP-mediated stimulation of transcriptional activity/cell proliferation occurred in an ER $\beta$-dependent manner. These effects were selectively observed with MBP, but not with the parent compound, BPA.

MBP, the culture medium, including MBP, was replaced with fresh medium together with MBP or vehicle. Therefore, in this experimental regimen (Fig. 2B), one possible criticism might be that the apparent effects of repeated exposure to MBP, booster $(+)$ versus booster $(-)$, can be simply explained by the difference in the "total" exposure of cells to MBP. Thus, we analyzed the effects of $2 \mathrm{nM}$ MBP on cells treated for 48 hours without the booster by a comparison of the effects of cells repeatedly exposed to $1 \mathrm{nM} \mathrm{MBP}$ [booster (+)] (see experimental regimen described in Fig. 9A). The obtained results of Western blotting indicated that in comparison with the booster (+) results with $1 \mathrm{nM} \mathrm{MBP}$, the expression of both $\mathrm{ER} \alpha$ and $\mathrm{ER} \beta$ proteins was significantly upregulated by $2 \mathrm{nM}$ MBP treatment (Fig. 9B). Furthermore, it was unexpectedly revealed that an inactive effect of PHTPP $(0.5 \mu \mathrm{M})$ on the cell viability after treatment at $2 \mathrm{nM}$ MBP for 48 hours without its booster was observed (Fig. 9C), implicating the involvement of the MBP-mediated $\mathrm{ER} \alpha$ activation.

\section{Discussion}

An accumulation of evidence suggests that BPA has a carcinogenic activity in the human breast because of its tumorpromoting properties (Seachrist et al., 2016). We are continually exposed to environmental BPA. In the current study, we investigated the effects of repeated exposure of BPA, together with MBP, at concentrations similar to environmental levels on the human breast cancer MCF-7 cell line, and demonstrated that 1) "repeated" exposure to MBP, but not parent BPA, stimulated the proliferation of MCF-7 cells through the mitogenic activity of cell cycle acceleration and 2) the bisphenol BPA used the ER $\beta$ subtype to induce mitogenic action.

It has been reported that BPA can be detected at concentrations between 0.3 and $40 \mathrm{nM}$ in human biologic samples from fetal serum and maternal plasma (Schönfelder et al., 2002; Welshon et al., 2006; Vandenberg et al., 2010). The combination of the data in Figs. 3 and 5, indicated the following: 1) although BPA can act as a positive stimulator of MCF-7 cell proliferation, as well as ER/ERE-mediated transcriptional activity, the former effect by this bisphenol at concentrations below $40 \mathrm{nM}$ (Fig. 3A) may not be fully indicated by the data in Fig. 5, A and B, because reasonably high concentrations of BPA are required to induce the full activation of ER/ERE-mediated transcriptional activity $(>500$ $\mathrm{nM}$ ); and, importantly, 2) it was revealed that in good accordance with the MBP-mediated stimulation of MCF-7 cell proliferation, which was observed at concentrations below $40 \mathrm{nM}$ (i.e., physiologic concentrations), the MBP-mediated activation of ER/ERE-mediated transcriptional activity in MCF-7 cells was also seen at concentrations below $40 \mathrm{nM}$, which implied the occurrence of a key interaction between the MBP activation of ERs and MCF-7 cell proliferation. Although the detailed regulation machinery of the $\mathrm{ER} \alpha / \beta$ protein associated with MBP exposure in MCF-7 cells is unknown at present, after consideration of these observations, it was suggested that MBP can use $\operatorname{ER} \beta$ (for which expression was unaffected) to induce its biologic effects (e.g., the stimulation of breast cancer cell proliferation) in $\mathrm{ER} \alpha / \beta$-positive cells after repeated exposure. Through the construction of the threedimensional analysis models of MBP with human $\mathrm{ER} \alpha / \beta$, it was suggested that MBP, but not BPA, interacted with amino acid residues in $\mathrm{ER} \alpha / \beta$ that were important for the binding of E2 in ERs (Baker and Chandsawangbhuwana, 2012). We have reported that the $\mathrm{EC}_{50}$ values for $\mathrm{ER} \alpha$ and $\mathrm{ER} \beta$ activation by MBP were 0.68 and $0.46 \mathrm{nM}$, respectively, in NIH/3T3 cells transfected with expression plasmids encoding human ER $\alpha$ or $\mathrm{ER} \beta$ (Yoshihara et al., 2004). Although we were unable to obtain the $\mathrm{EC}_{50}$ values for the individual subtypes of $\mathrm{ER} \alpha$ and $\mathrm{ER} \beta$ after the activation by MBP in MCF-7 cells, it was suggested that MBP may behave as an equipotent activator of human $\mathrm{ER} \alpha / \beta$.

In this study, it was also revealed that BPA itself can stimulate MCF-7 cell proliferation at concentrations below $40 \mathrm{nM}$; as recently reported, this effect of BPA might be mediated by nuclear ER-independent signaling pathways: 1) Shimohigashi and Matsushima's research group reported that BPA had a high affinity $\left(K_{\mathrm{d}}=5.50 \mathrm{nM}\right)$ for orphan nuclear receptor estrogen-related receptor $\gamma$ and that the interaction between BPA and estrogen-related receptor $\gamma$ may explain the biologic effects of low-dose BPA (Takayanagi et al., 2006; Okada et al., 2008); and 2) BPA targets G-protein coupled estrogen receptor (GPR30/GPER) expressed in the cell membrane to cause nongenomic estrogenic signaling (Dong et al., 2011; Ge et al., 2014). Exposure to environmental chemicals may be associated with many undesirable health outcomes; however, the negative effects of these environmental chemicals are generally weakened by drug-metabolizing enzymes (phase I and II reactions) after exposure. In the case of BPA, it has been reported that under in vivo conditions, BPA is readily converted to BPA-glucuronide (via phase II reaction); however, BPAglucuronide has itself also been proven to be a possible active metabolite that induces adipogenesis in human and murine preadipocytes (Boucher et al., 2015). Although it has been suggested that $\operatorname{ER} \beta$ has a possible protective role against breast tumor progression, the accumulated evidence suggests that $\mathrm{ER} \beta$ also acts as a mediator of estrogen action, coupled with tumorigenesis, in breast cancer cells, and that its expression is remarkably upregulated in tamoxifen-resistant breast cancers (Dotzlaw et al., 1999; Speirs et al., 1999a,b; Power and Thompson, 2003; Hamilton et al., 2015; Ma et al., 2017). Collectively, including our findings here, it is suggested that the negative biologic effects of BPA are exerted through several 
methods, such as through BPA itself and BPA metabolites, including BPA-glucuronide and MBP, and that the MBPmediated estrogenic effects on breast cancer cells, which were possibly amplified by repeated exposure, were mediated by ER $\beta$ (Fig. 10).

\section{Authorship Contributions}

Participated in research design: Takeda.

Conducted experiments: Hirao-Suzuki, Okuda.

Performed data analysis: Hirao-Suzuki, Takeda.

Wrote or contributed to the writing of the manuscript: Hirao-Suzuki, Takeda, Okuda, Takiguchi, Yoshihara.

\section{References}

Baker ME and Chandsawangbhuwana C (2012) 3D models of MBP, a biologically active metabolite of bisphenol $\mathrm{A}$, in human estrogen receptor $\alpha$ and estrogen receptor $\beta$. PLoS One 7:e46078.

Boucher JG, Boudreau A, Ahmed S, and Atlas E (2015) In vitro effects of bisphenol A $\beta$-D-glucuronide (BPA-G) on adipogenesis in human and murine preadipocytes. Environ Health Perspect 123:1287-1293.

Brotons JA, Olea-Serrano MF, Villalobos M, Pedraza V, and Olea N (1995) Xenoestrogens released from lacquer coatings in food cans. Environ Health Perspect 103 : $608-612$

Calafat AM, Ye X, Wong LY, Reidy JA, and Needham LL (2008) Exposure of the U.S population to bisphenol A and 4-tertiary-octylphenol: 2003-2004. Environ Health Perspect 116:39-44.

Cowley SM, Hoare S, Mosselman S, and Parker MG (1997) Estrogen receptors $\alpha$ and $\beta$ form heterodimers on DNA. J Biol Chem 272:19858-19862.

Dong S, Terasaka S, and Kiyama R (2011) Bisphenol A induces a rapid activation of Erk1/2 through GPR30 in human breast cancer cells. Environ Pollut 159.212-218.

Dotzlaw H, Leygue E, Watson PH, and Murphy LC (1999) Estrogen receptor- $\beta$ messenger RNA expression in human breast tumor biopsies: relationship to steroid receptor status and regulation by progestins. Cancer Res 59:529-532.

Duong V, Licznar A, Margueron R, Boulle N, Busson M, Lacroix M, Katzenellenbogen BS, Cavaillès V, and Lazennec G (2006) ERalpha and ERbeta expression and transcriptional activity are differentially regulated by HDAC inhibitors. Oncogene 25:1799-1806

EPA (2011) Estrogen receptor transcriptional activation (human cell line - HeLa9903). U.S. Environmental Protection Agency, Washington, DC.

Foster JS, Henley DC, Bukovsky A, Seth P, and Wimalasena J (2001) Multifaceted regulation of cell cycle progression by estrogen: regulation of Cdk inhibitors and Cdc25A independent of cyclin D1-Cdk4 function. Mol Cell Biol 21:794-810.

Ge LC, Chen ZJ, Liu HY, Zhang KS, Liu H, Huang HB, Zhang G, Wong CK, Giesy JP, $\mathrm{Du}$ J, et al. (2014) Involvement of activating ERK1/2 through G protein coupled receptor 30 and estrogen receptor $\alpha / \beta$ in low doses of bisphenol A promoting growth of Sertoli TM4 cells. Toxicol Lett 226:81-89.

Hamilton N, Marquez-Garban D, Mah VH, Elshimali Y, Elashoff D, Garon EB Vadgama J, and Pietras R (2015) Estrogen receptor- $\beta$ and the insulin-like growth factor axis as potential therapeutic targets for triple-negative breast cancer. Crit Rev Oncog 20:373-390.

Ishibashi H, Watanabe N, Matsumura N, Hirano M, Nagao Y, Shiratsuchi H, Kohra S, Yoshihara S, and Arizono K (2005) Toxicity to early life stages and an estrogenic effect of a bisphenol A metabolite, 4-methyl-2,4-bis(4-hydroxyphenyl)pent-1-ene on the medaka (Oryzias latipes). Life Sci 77:2643-2655.

Iwao K, Miyoshi Y, Egawa C, Ikeda N, and Noguchi S (2000) Quantitative analysis of estrogen receptor- $\beta$ mRNA and its variants in human breast cancers. Int $J$ Cancer 88:733-736.

Krishnan AV, Stathis P, Permuth SF, Tokes L, and Feldman D (1993) Bisphenol-A: an estrogenic substance is released from polycarbonate flasks during autoclaving. Endocrinology 132:2279-2286.

Kuiper GG, Carlsson B, Grandien K, Enmark E, Häggblad J, Nilsson S, and Gustafsson JA (1997) Comparison of the ligand binding specificity and transcript tissue distribution of estrogen receptors alpha and beta. Endocrinology 138: $863-870$.

Kundakovic M, Gudsnuk K, Franks B, Madrid J, Miller RL, Perera FP, and Champagne FA (2013) Sex-specific epigenetic disruption and behavioral changes following low-dose in utero bisphenol A exposure. Proc Natl Acad Sci USA 110:9956-9961.

Ma R, Karthik GM, Lövrot J, Haglund F, Rosin G, Katchy A, Zhang X, Viberg L, Frisell J, Williams C, et al. (2017) Estrogen receptor $\beta$ as a therapeutic target in breast cancer stem cells. $J$ Natl Cancer Inst 109:1-14.

Miki Y, Suzuki T, Tazawa C, Yamaguchi Y, Kitada K, Honma S, Moriya T, Hirakawa H, Evans DB, Hayashi S, et al. (2007) Aromatase localization in human breast cancer tissues: possible interactions between intratumoral stromal and parenchymal cells. Cancer Res 67:3945-3954.

Moreman J, Takesono A, Trznadel M, Winter MJ, Perry A, Wood ME, Rogers NJ, Kudoh T, and Tyler CR (2018) Estrogenic mechanisms and cardiac responses following early life exposure to bisphenol A (BPA) and its metabolite 4-Methyl-2,4bis( p-hydroxyphenyl)pent-1-ene (MBP) in zebrafish. Environ Sci Technol 52: $6656-6665$.

Nawaz Z, Lonard DM, Dennis AP, Smith CL, and O'Malley BW (1999) Proteasomedependent degradation of the human estrogen receptor. Proc Natl Acad Sci USA 96:1858-1862.
Nirmala PB and Thampan RV (1995) Ubiquitination of the rat uterine estrogen receptor: dependence on estradiol. Biochem Biophys Res Commun 213:24-31.

Ogawa S, Inoue S, Watanabe T, Orimo A, Hosoi T, Ouchi Y, and Muramatsu M (1998) Molecular cloning and characterization of human estrogen receptor betacx: a potential inhibitor ofestrogen action in human. Nucleic Acids Res 26:3505-3512.

Okada H, Tokunaga T, Liu X, Takayanagi S, Matsushima A, and Shimohigashi Y (2008) Direct evidence revealing structural elements essential for the high binding ability of bisphenol A to human estrogen-related receptor- $\gamma$. Environ Health Perspect 116:32-38.

Okazaki H, Hirao-Suzuki M, Takeda S, Takemoto Y, Mizunoe R, Haraguchi K, Watanabe K, Takiguchi M, and Aramaki H (2018) Bisphenol AF as an activator of human estrogen receptor $\beta 1$ (ER $\beta 1)$ in breast cancer cell lines. J Toxicol Sci 43 : $321-327$

Okuda K, Takiguchi M, and Yoshihara S (2010) In vivo estrogenic potential of 4-methyl-2,4-bis(4-hydroxyphenyl)pent-1-ene, an active metabolite of bisphenol A, in uterus of ovariectomized rat. Toxicol Lett 197:7-11.

Olea N, Pulgar R, Pérez P, Olea-Serrano F, Rivas A, Novillo-Fertrell A, Pedraza V, Soto AM, and Sonnenschein C (1996) Estrogenicity of resin-based composites and sealants used in dentistry. Environ Health Perspect 104:298-305.

Pettersson K, Delaunay F, and Gustafsson JA (2000) Estrogen receptor $\beta$ acts as a dominant regulator of estrogen signaling. Oncogene 19:4970-4978.

Powell E and Xu W (2008) Intermolecular interactions identify ligand-selective activity of estrogen receptor $\alpha / \beta$ dimers. Proc Natl Acad Sci USA 105:19012-19017.

Power KA and Thompson LU (2003) Ligand-induced regulation of ERalpha and ERbeta is indicative of human breast cancer cell proliferation. Breast Cancer Res Treat 81:209-221.

Richter CA, Taylor JA, Ruhlen RL, Welshons WV, and Vom Saal FS (2007) Estradiol and bisphenol A stimulate androgen receptor and estrogen receptor gene expression in fetal mouse prostate mesenchyme cells. Environ Health Perspect 115: 902-908.

Schönfelder G, Wittfoht W, Hopp H, Talsness CE, Paul M, and Chahoud I (2002) Parent bisphenol A accumulation in the human maternal-fetal-placental unit. Environ Health Perspect 110:A703-A707.

Seachrist DD, Bonk KW, Ho SM, Prins GS, Soto AM, and Keri RA (2016) A review of the carcinogenic potential of bisphenol A. Reprod Toxicol 59:167-182.

Speirs V, Malone C, Walton DS, Kerin MJ, and Atkin SL (1999a) Increased expression of estrogen receptor $\beta$ mRNA in tamoxifen-resistant breast cancer patients. Cancer Res 59:5421-5424.

Speirs V, Parkes AT, Kerin MJ, Walton DS, Carleton PJ, Fox JN, and Atkin SL (1999b) Coexpression of estrogen receptor $\alpha$ and $\beta$ : poor prognostic factors in human breast cancer? Cancer Res 59:525-528.

Steinmetz R, Brown NG, Allen DL, Bigsby RM, and Ben-Jonathan N (1997) The environmental estrogen bisphenol A stimulates prolactin release in vitro and in vivo. Endocrinology 138:1780-1786.

Suzuki M, Takeda S, Okazaki H, Watanabe K, Takiguchi M, and Aramaki H (2017a) Cannabidiolic acid-mediated interference with AP-1 transcriptional activity in MDA-MB-231 breast cancer cells. Nat Prod Commun 12:759-761.

Suzuki M, Takeda S, Teraoka-Nishitani N, Yamagata A, Tanaka T, Sasaki M, Yasuda N, Oda M, Okano T, Yamahira K, et al. (2017b) Cadmium-induced malignant transformation of rat liver cells: potential key role and regulatory mechanism of altered apolipoprotein $\mathrm{E}$ expression in enhanced invasiveness. Toxicology 382:16-23.

Takayanagi S, Tokunaga T, Liu X, Okada H, Matsushima A, and Shimohigashi Y (2006) Endocrine disruptor bisphenol A strongly binds to human estrogen-related receptor $\gamma$ (ERRgamma) with high constitutive activity. Toxicol Lett 167:95-105.

Takeda S (2014) $\Delta^{9}$-Tetrahydrocannabinol targeting estrogen receptor signaling: the possible mechanism of action coupled with endocrine disruption. Biol Pharm Bull 37:1435-1438.

Takeda S, Okazaki H, Kudo T, Kakizoe K, Himeno T, Matsumoto K, Shindo M, and Aramaki H (2016) Bongkrekic acid as a Warburg effect modulator in long-term estradiol-deprived MCF-7 breast cancer cells. Anticancer Res 36:5171-5182.

Takeda S, Yoshida K, Nishimura H, Harada M, Okajima S, Miyoshi H, Okamoto Y, Amamoto T, Watanabe K, Omiecinski CJ, et al. (2013) $\Delta\left({ }^{9}\right)$-Tetrahydrocannabinol disrupts estrogen-signaling through up-regulation of estrogen receptor $\beta$ (ER $\beta$ ). Chem Res Toxicol 26:1073-1079.

Vandenberg LN, Chahoud I, Heindel JJ, Padmanabhan V, Paumgartten FJ, and Schoenfelder G (2010) Urinary, circulating, and tissue biomonitoring studies indicate widespread exposure to bisphenol A. Environ Health Perspect 118 1055-1070.

Weigel RJ and deConinck EC (1993) Transcriptional control of estrogen receptor in estrogen receptor-negative breast carcinoma. Cancer Res 53:3472-3474.

Welshons WV, Nagel SC, and vom Saal FS (2006) Large effects from small exposures. III. Endocrine mechanisms mediating effects of bisphenol A at levels of human exposure. Endocrinology 147 (6 Suppl):S56-S69.

Yamamoto T and Yasuhara A (1999) Quantities of bisphenol a leached from plastic waste samples. Chemosphere 38:2569-2576.

Yoshihara S, Makishima M, Suzuki N, and Ohta S (2001) Metabolic activation of bisphenol A by rat liver S9 fraction. Toxicol Sci 62:221-227.

Yoshihara S, Mizutare T, Makishima M, Suzuki N, Fujimoto N, Igarashi K, and Ohta S (2004) Potent estrogenic metabolites of bisphenol A and bisphenol B formed by rat liver S9 fraction: their structures and estrogenic potency. Toxicol Sci 78:50-59.

Address correspondence to: Shuso Takeda, Laboratory of Xenobiotic Metabolism and Environmental Toxicology, Faculty of Pharmaceutical Sciences, Hiroshima International University (HIU), 5-1-1 Hiro-koshingai, Kure, Hiroshima 737-0112, Japan. E-mail: s-takeda@hirokoku-u.ac.jp 